admitted that they could never recognize a shape, there was only a " feeling that there was something there:" something too ill defined to describe. These indefinite formas. appeaxed only in the early stages and generally in blind ameas that were: recovering. They are probably due the misinterpetation of feeble and indefinite sensations excited in functionally depressed areas of the visual cortex.

\section{A CASE OF SYMMETRICAL GANGRENE (RAYNAUD'S DISEASE).}

BY

BDWIN GUODALL, M.D.LoND., B.S., F.R.C.P., TEMTP. LTEUT.-CoLONEL R.A.M.C.,

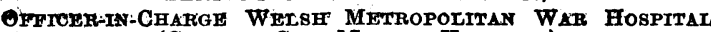

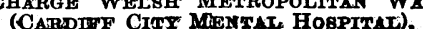

Thro patient whose case is here related was admitted on May 22nd, 1919, to the Welsh Metropolitan War Hospital from the Bath War Hospital with a diagnosis of subacute mania; possibly general paralysis of the insane. It was reported that the pupils were: unequal and sluggish, that there were facial and lingual tremors and greasiness of the skin of the face. The duration of the mental attack was given as four deys.

History. Patient was 42 years of agte.
The information supplied by his wife showed nothing of note in respect of family or note in respect of family or personal history. His presupervened after five years' military service. The following are extracts from the medical case-sheet received on admission of the patient to this hospital, the medteal
notes having been taken whilst at a hospital in Cairo:

Admitted on March 26th, 1919, suffering from bronchitis, bropan nod also natches of bronchopoted. also patches of bronchopleuriticie rub below right breast On April llth diarrhoea, with blood and nucus in evacuatons; no protozoa; no history of dysentery; urfne alkaline. albumin present with phos-

On. Apris 17th geogreve threatening the right. footh with lo cold and ine; pain occasional trace of olbumin. no casts, no sugar.

On April 18th left foot bluish right; foot inpproved; little and

On April 20th gangrene threatening both hands, more in right; blue nd cold, numb, painful

On April Ocovered

On. April 28th. hands a.little better; fingers still black

iil bioligh, The tationt was' sto to have had malario bo, and cald

On admission to this hospital it was noted that he showed general wasting : the radial arteries were somewhat thickened; the temporsles were nat evident. No abnommality of herrt; tremar of hande and tongue, and ungteadiness of gait; speech normal; pupils equed, react normally to light. and aecommadetion,; kneerjerks brislo; sapexficial reflexes normal. Systolic blood pressure 152, diastolic 130.

The blood was examined. on May 29th and June 17th, with the

Ried blood corpuscles $4,933,333$ and $5,360,000$ to the c.mm.; white blood conpusetes 7,383 and 13,750; haemoglobin pencentage, 85 and 95 clour. index, 0.87 and 0.95; relative: white cell count shows laxg 3.5 par cent. On the second ogeasion these finuree T5.25 per cent. (Iymphooytosia). No other peculisrities?

iw urine was examined on three occasions-

May 27th: Specific gravity 1026; acid; no guigar; no albumin.

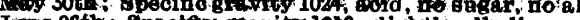

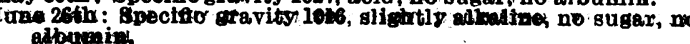

The "Wassermann," reaction, for which I am indebted to Captecin H. A. Scholberg. R.A.M.C.(T.), was negative in serum and in cerebrospinal fuid. Cells in cerebro-spinal fluid 2 to the c.mm. Nitrogen in i cm is estimate hospital) 14.5 hapdredth

Although the patient was restless, garrulous, excited and grandiose; he was not, according to the above laboratory findings, a general paralytic. The photographs sufficiently indicate the state of the fingers. The dark portions were gangrenous-black, dry, and insensitive; the nails were still gangrenous-black, dry, and insensitive; the nails were still
preserved on each finger. The skin of the fingers above the gangrenous! portions was reddish-blue, tense, shiny and sensitive to touch; the gangrenous portions, although insensitive to light touch, were sensitive to pin-prick and to deep pressure. The hands generally were somewhat livid; toes, nose, and ears not affected.

On June 30th, the date of writing this report, the patient appears to be almost well from what was presumably an attack of subacute mania There are no physical indications of general paral.jsis. It is noted, however, thent both pupils are slightly excentric, and there is greasiness of the facial. skin. Systolic blood pressure 148, disstolic blood pressure. 128: mummification of affected finger-tips; lime of demarcation between living and dead portions veny obviousi

Raynaud, in his original thesis, published in 1862 states that, out of 25 cases of symmetrical gangrene seen by him; 20 ocenrred in women and 5 in men the patients were all under 30, excepting one aged 48. Oppenheim ${ }^{1}$ describes the disease as developing exclusively or principally on the basis of the. "nearo. pathic diathesis." Amongst exciting causes, emotional disturbances-fear, etc. take first place. Sometimes the condition has been preceded by infectious disease - typhoid, in. fluenza. Young women up to 30 years of age are the usual victims, bat. of the 4 cases which Opponheim had seen 3 were men. Photographs of the condition given in Oppen. heim's work are: almost identical with those accom. panying the present description. In Raynoud's Plate 1, showing the toes of two feet affected by symmetrical gangrene, the condition is much less advanced than in the case here recorded. For the photographs accompanying these notes I am indebted to Dr. Stanford.

There is no question in this case of ergotism. The bread eaten by this. patient whilst in Egypt was the same as that. issued to the troops in general. I do not recollect. a single instance of this disease amongst the cases of mental disorder seen by me, whether in public institutions or consulting practice, during my twenty.nine years' experience:

I. desire to take this: opportanity to draw attention to the micro-quantitative methods of estimating the constituents of cerebro-spinal fluid devised by Dr. R. V. Stanford. That for nitrogen is described in the $Z$ eitschrift für Physiologische: Chemie (Bd. 86, H. 3, of 1913). Details of the results in a large number of coses are given in that paper, and a great many mare have been dealt with since. The conclusions are: summarized as follows in a memorandum ' kindIy supplied to me by Stanford:

The number of hundredths of a milligram of total nitrogen contained in $1 \mathrm{c.cm}$. of the cerebrorspinal fluid of a patientis called the "nitrogen number" (NN). In the normal sane individual the nitrogen number is about 15 . In the grest majority of insane patients, not suffering from general panalysis or gross brain lesion, the NN is between. 15 and: 20 . Im few cases it was found to be higher, but in ony cone case above.26. In cases of general paralysis the nitropen number is newis 
always above 20; and generally about 30 or more. In a small percentage of cases a nitrogen number below 20 was found, but percentage of cases a nitrogen number below 20 was found, but called a stationary state. In such cases a second puncture calter an interval of time would probably settle the diagnosis (compare Table I, bis, loc. cit.). Details are given in the paper cited, where will also be found the figures relating to a patien who was examined when in remission, and subsequently, when the disease had resumed its course, the nitrogen number varied accordingly.

One other exception must be pointed out. The wasted brain of the senile dement is well known post mortem. Corresponding with this, it is found that patients who have been insane for a long period, especially if of advanced years, have high nitrogen numbers. Such cases would, however, never be confused with cases of general paralysis. Regarded as an aid to diagnosis in general paralysis, the nitrogen number is ver much mor reliable than ony state of the investigation of the subject it must be taken in eonjunction with the clinical observations.

The above reference to Stanford's method is made with a view to promoting its use as a routine procedure in diagnosis, in cases of organic and functional disease, as sein in neurological and psychiatric practice.

Letirbuch der Nervenkirankheiten.

\section{THE EFFECTS OF A SCORBU'CIC DIET ON THE ADRENAL GLANDS.*}

\author{
BY
}

ROBERT McCARRISON, M.D., D.Sc., F.R.C.P., Brevet Libutranant-Coloned I.M.S.

(From the Pasteur Institute of 8. India, Coonoor.)

Tre effects of a scorbutic diet on the adrenal glands have been studied in guinea-pigs fed on a dietary of crushed oats and autoclaved milk. The naked-eye changes consist in enlargement of the adrenals with increase in their weight and in congestion.

The weight of the adrenals of guinea-pigs dying in consequence of the scorbutic diet is approximately double that of health. Whereas the gross weight of both organs in healthy guinea-pigs ranged between 0.390 and 0.520 , with an average weight of $0.467 \mathrm{gram}$, in guinea-pigs fed on the scorbutic dietary the weight of both glands ranged between 0.850 and 1.150 grams, with an average weight of 0.955 gram. The increase in weight due to the scorbutic diet is even more marked when the weight of the glands is calculated per kilo of original and of final body-weight.

The histo-pathological changes are haemorrhagic infil. tration and disintegration of the cellular elements of the cortex and medulla. These changes occur in animals which may exhibit no clinical evidences of scurvy during life. They are to be regarded as pre-scorbutic in character. The areas of haemorrhagic infiltration are circumscribed, and are situated around the periphery of the adrenal cortex.

The adrenalin content of the suprarenals of gumea-pigs fed on a scorbutic dietary was estimated in five animals by the method of Folin, Cannon, and Dennis. One gland was used for this estimation and the other for histological study. In some cases the right and in others the left gland was used for the estimation. There is no evidence that the organ on one side is more affected than that on the other. On the presumption that each was affected to a like degree the total adrenalin content of both adrenals was calculated from the results obtained with one gland.

It was found that in spite of the fact that the weight of the organs is more than twice as great, the total quantity of adrenalin in the two glands in guinea-pigs fed on a scorbutic diet is less than half that present in healthy guinea-pigs. Similarly the total adrenalin per kilo of original body-weight (that is, the weight of the animal before the experiment commenced) is little more than half that of health. When calculated against the final body. weight of the guinea-pig the total adrenalin per kilo of body-weight is found to be less markedly reduced-that is to say, the total adrenalin production does not diminish in proportion to the diminution of body-weight. The total adrenalin per gram of gland is less than one-fourth of that found in health. In one guinea-pig in which a coliform organism was cultivated from the heart's blood at autopsy,

* Abstract of a paper appearing in the July number of the Indian Journal of Medical Research. Abstracts of previous papers on the Mrepon Jod of Defich on February 15th, 1919, p. 177, and on July 12th last, p. 36 . the adrenalin content was considerably less than in the other four animals in which no infection was detected by aërobic methods of culture.

A pronounced reduction in the amount of adrenalin in the suprarenal glands is thus found to result in guinea-pigs from a scorbutic dietary of crushed oats and autoclaved milk.

It is of interest to direct attention to the fact that the total adrenalin per gram of gland in healthy pigeons is approximately ten times greater $(0.0023$ gram $)$ than in healthy guinea-pigs $(0.00023$ gram). This greater pro. portion may bear some relation to the fact that urie acid is excreted as such in aves. A further point of interest in connexion with these results in guinea-pigs is the contrast they afford to the great increase in the adrenalin content of the adrenal glands which occurs in pigeons wholly deprived of accessory food factors of all classes. I have found that the adrenalin content of these organs in aves is largely dependent on the class of accessory food factor which is absent from the dietary. When, for example, fresh butter, which contains accessory food factors of the "A" class, is added to a dietary of autoclaved rice, the adrenal glands of pigeons so fed do not, as a rule, contain an amount of adrenalin out of proportion to that found in health; exceptions occur in approximately 10 per cent, of all pigeons so fed. Nevertheless, the evidence so far arail. able, both in birds and mammals, points to the dependence of the functional perfection of the adrenal glands on the adequate provision in the food of accessory food factors of all classes. It appears that lack of factors of -the " $A$ " class with excessive production of adrenalin is associated with the occurrence of oedema in aves, and that in guineapigs lack of factors of the " $\mathrm{C}$ " class, with diminished production of adrenalin, is associated with haemorrhage into the body tissues.

\section{SUDDEN DETACHMENT OF AORTIC INTIMA (SO-CALLED DISSECTING ANEURYSM).}

CRANSTON WALKER, M.D., B.Sc., Pathologist, birmingham general hospital, eto., AND

LENA WALKFR, M.D., Сн.B.

Thz clinical events in the following case may be attributed to the stripping of the aortic intima. From the history of a very sudden onset, without any previous warnings, it may be assumed that the intima began to strip suddenly, that it gave rise to severe shock, and to pain which was referred rather vaguely. The condition of the left leg was probably due to a portion of the loose intima happening to occlude, completely or partially, one of the main arteries to the limb and so shutting off too much blood supply for full muscular metabolism to : be carried on; later, collateral channels would be opened up.

As the shock from this stripping nearly killed the patient before his admission, it may be surmised that his sudden death after admission was due to the onset of a second stripping, although two such events could not be traced post mortem.

Clinical History.

The patient was a large, well built, muscular man of 65 , a plasterer, a steady and respected workman and apparently of temperate habits. He had had no recognized illness since be in hearty good health up to the moment of his sudden seizure.

At 10.30 a.m., after no particular exertion or excitement, he fell to the ground without warning. It is uncertain whether he lost consciousness-bystanders described the occurrence as a "fit"-but within a few minutes he was seen to be consclous a "fit"-but within a few minutes he was seen to be consclous and a little later complained of psin

He was admitted to the General Hospital, Birmingham, about three-quarters of an hour after the event. He was fully conscious, but distracted by abnormal sensations. He complained chiefly of pain and loss of use in the left leg, and also of pain under the sternum; but his chief cause of distrese appeared to be some oppressive sensation or conviction fo: which no words came bandy. He felt certain he was about to die. He was restless and pallid, the skin surface was rather cool, the respirations were irregular, rather rapid, and frequently deepened voluntarily. Thus far his aspect was like that of a man suffering from a severe haemorrhage and from pain. 